\title{
Boron Nitride Nanoporous Membranes with high surface charge by
}

\section{Atomic Layer Deposition}

Matthieu Weber ${ }^{1}$, Boonprakrong Koonkaew ${ }^{1}$, Sebastien Balme1, Ivo Utke ${ }^{2}$, Fabien Picaud², Igor latsunskyi ${ }^{4}$, Emerson Coy ${ }^{4}$, Philippe Miele ${ }^{1}$ and Mikhael Bechelany ${ }^{1 *}$

1 Institut Européen des Membranes, IEM-UMR 5635 ENSCM, UM, CNRS, Université de Montpellier, Place Eugène Bataillon, 34095 Montpellier Cedex 5, France

2 EMPA, Swiss Federal Laboratories for Materials Science and Technology, Laboratory for Mechanics of Materials and Nanostructures, Feuerwerkerstrasse 39, CH-3602 Thun, Switzerland

${ }^{3}$ Laboratoire de Nanomédecine, Imagerie et Thérapeutique, EA4662, Université Bourgogne-Franche-Comté, Centre Hospitalier Universitaire de Besançon, 16 route de Gray, 25030 Besançon, France

${ }^{4}$ NanoBioMedical Centre, Adam Mickiewicz University in Poznan, 61-614, Umultowska str. 85 Poznan, Poland

*Corresponding authors : mikhael.bechelany@umontpellier.fr, Phone: +33467149167, Fax: +33467149119

Keywords : Atomic Layer Deposition, Boron Nitride, Membrane, Surface charge, Nanotechnology.

\section{ABSTRACT}

In this work, we report the design and the fine-tuning of boron nitride single nanopore and nanoporous membranes by atomic layer deposition (ALD). First, we developed an ALD process based on the use of $\mathrm{BBr}_{3}$ and $\mathrm{NH}_{3}$ as precursors in order to synthesize $\mathrm{BN}$ thin films. The deposited films were characterized in terms of thickness, composition and microstructure. Next, we used the newly developed process to grow BN films on anodic 
aluminium oxide (AAO) nanoporous templates, demonstrating the conformality benefit of BN prepared by ALD, and its scalability for the manufacturing of membranes. For the first time, the ALD process was then used to tune the diameter of fabricated single transmembrane nanopores by adjusting the BN thickness and to enable studies of the fundamental aspects of ionic transport on a single nanopore. At $\mathrm{pH}=7$, we estimated a surface charge density of $0.16 \mathrm{C} . \mathrm{m}^{-2}$ without slip and $0.07 \mathrm{C} . \mathrm{m}^{-2}$ considering a reasonable slip length of $3 \mathrm{~nm}$. Molecular dynamic simulations performed with experimental conditions confirmed the conductivities and the sign of surface charges measured. The high ion transport results obtained and the ability to fine-tune nanoporous membranes by such a scalable method paves the way towards applications such as ionic separation, energy harvesting and ultrafiltration devices.

\section{INTRODUCTION}

Boron nitride (BN) is a III-V material known for its outstanding physico-chemical properties and particularly its high chemical stability. ${ }^{1}$ The hexagonal polymorph (h-BN) presents a wide band-gap (5.5-6.0 eV) and a microstructure compatible with graphene due to its layered structure based on $\mathrm{B}_{3} \mathrm{~N}_{3}$ hexagons, which makes it potentially suitable for dielectric layers in electronic devices. ${ }^{2-3}$ Thus, in the past decades, the direct growth of boron nitride films has attracted a lot of interest because of its potential for 2D-based devices..$^{2,4}$ However, recent works have unveiled new perspectives for this material, and thus the development of $\mathrm{BN}$ films is also strongly motivated by their application in nanofluidics. Nanofluidics is a topic at the forefront of research efforts, as the understanding of this field 
has the potential to find many applications in sensing, ${ }^{5-8}$ ultrafiltration, ${ }^{9-12}$ water desalination, ${ }^{13-14}$ or renewable energy. ${ }^{15-17}$

Recently, Liu and Li demonstrated the efficiency of BN nanoporous membranes for water cleaning. ${ }^{11-12}$ The $\mathrm{BN}$ membranes exhibited high effectiveness and stability in the purification of simulated wastewater. ${ }^{11-12}$ In addition, Siria and co-workers ${ }^{15}$ have predicted that BN nanopores, presenting high surface charge densities and/or short lengths, make excellent candidates for osmotic energy harvesting, ${ }^{15-18}$ which would enable renewable energy to be extracted from the difference in salinity between fresh and salty water. ${ }^{19-20}$ In fact, the surface charge of a nanopore affects its direct interactions with charged macromolecules, and is also at the origin of electro-osmotic flux which governs the charged or uncharged macromolecule translocation. The nanopore surface charge, which is linked to the constant conductivity at low salt concentrations, is thus of key importance. The chemical nature and the origin of the charges at the BN surface are not yet fully understood. The origin of those charges may be linked to defects in the large bandgap of the ionic h-BN system (the planar hexagonal $\mathrm{BN}$ sheet), leading to open-shell in-gap states prone to capturing charges. ${ }^{15,21}$ As the electron deficient B atoms possess Lewis acid characteristics, the ionically active surface charges may also be due to the locally polarized $\mathrm{B}-\mathrm{N}$ bonds. ${ }^{22}$

The increase of the surface charge density in a solid-state nanopore can be obtained by shining a laser beam within the pore, ${ }^{23}$ but a more straightforward route is to tune the solid-state material itself. Up to date, the fabrication of solid-state nanoporous membranes with single-nanometer precision is extremely challenging and suitable and scalable routes for the large scale manufacturing of both single and multipores BN membranes are thus desired. 
Atomic layer deposition (ALD) is a vapor phase deposition technique enabling the synthesis of various materials with a sub-nanometer thickness control. ${ }^{24-29}$ Due to its inherent self-limiting surface reactions, ALD processes can be developed to control the surface of nanopores with single-nanometre precision. For example, $\mathrm{ALD}$ of $\mathrm{Al}_{2} \mathrm{O}_{3}$ and $\mathrm{ZnO}$ have been used in the past to fine-tune the surface properties and diameters of fabricated nanopores ${ }^{30-31}$ and to coat conformally nanoporous membranes. ${ }^{32-35}$ ALD is also well known for its scalability. ALD processes are currently used for the most challenging thin-film deposition applications where the scalability is essential such as microelectronics, as ALD is used for the preparation of high $\mathrm{k}$ oxides gates in transistors. ${ }^{24,36}$ Furthermore, the scalability of ALD has also been demonstrated on membranes. For example, our group previously applied ALD for the coating of commercial (Pall) membranes. ${ }^{37}$

ALD of $B N$ is challenging and processes with different precursors have been attempted in the past. ${ }^{38-49}$ So far, there is no report of BN being deposited on nanostructures such as micro/nano porous membranes by ALD, and the conformality of the different processes reported have not been studied.

ALD of $B N$ is not trivial and such process with different precursors has been attempted in the past. Using sequential exposures of triethylboron (TEB) and $\mathrm{N}_{2} / \mathrm{H}_{2}$ plasma, Haider et al. deposited polycrystalline BN films, but no self-limiting growth behavior has been observed. ${ }^{39}$ By means of the same TEB precursor but using $\mathrm{NH}_{3}$ as co-reactant, Snure et al. also achieved to grow crystalline BN films, however the self-limiting growth was not observed at the deposition temperature of $900^{\circ} \mathrm{C}$, indicating a CVD-like deposition mode. ${ }^{47}$ $\mathrm{BCl}_{3}$ and $\mathrm{NH}_{3}$ have also been investigated as sources for ALD of $\mathrm{BN}$. In the early study of 2002, the group of George deposited $\mathrm{BN}$ films from $\mathrm{BCl}_{3}$ and $\mathrm{NH}_{3}$, and monitored the ALD 
surface reactions using Fourier-transform infrared (FTIR) spectroscopy. The films deposited were amorphous, but the uniformity and conformality of the coatings were achieved. ${ }^{44}$ Mono and multi layers of hexagonal BN have been grown using the same precursors, ${ }^{45-46,48}$ showing the potential of the technique for the preparation of $B N 2 D$ materials, but one has to note that the substrates used, $\mathrm{Ru}(0001)$ and $\mathrm{Co}(0001)$, have a strong influence on the ordering of the deposited h-BN layers. In their recent study, Consiglio et al. used $\mathrm{BCl}_{3}$ and $\mathrm{NH}_{3}$ to grow BN films at $630^{\circ} \mathrm{C} .{ }^{38}$ The microstructure of the films was not investigated in their work, which focused on the doping capabilities and the thermal resistance properties. The BN films were found to be thermally resistant in terms of thickness that did not decrease after the annealing step at $1000^{\circ} \mathrm{C}$, which is also consistent with the refractory nature of $\mathrm{BN}$. In the last reported work on BN ALD, Park et al. developed a plasma-assisted process using a home-synthesized precursor (tris(ethylmethylamino) borane) and prepared uniform BN films for electronic applications. Although the process reported is promising, the use of plasma hinders the conformality benefit of ALD and its use for particular applications such as the coating of micro/nano porous membranes. ${ }^{49}$

$\mathrm{BBr}_{3}$ is a precursor with a very high vapor pressure $\left(70\right.$ Torr at $\left.25^{\circ} \mathrm{C}\right),{ }^{50}$ which reacts readily with ammonia. Using Density Functional Theory, the initial growth of boron nitride has been investigated and the results obtained indicated that $\mathrm{BBr}_{3}$ and $\mathrm{NH}_{3}$ are a promising combination of gaseous precursors for BN ALD. ${ }^{41}$ Furthermore, considering that the reactivity increases for halogenated compounds of boron from chlorine to bromine, we believe $\mathrm{BBr}_{3}$ is the most suitable precursor candidate to achieve ALD of BN. During the initial precursor exposure, $\mathrm{BBr}_{3}$ is expected to react efficiently with the hydroxyl groups of an oxide substrate surface. During growth, the ALD chemistry of this process is divided in the anticipated two-half reactions: 


$$
\begin{aligned}
& \mathrm{BBr}^{*}+\mathrm{NH}_{3} \rightarrow \mathrm{BNH}_{2}{ }^{*}+\mathrm{HBr} \\
& \mathrm{BNH}_{2}{ }^{*}+\mathrm{BBr}_{3} \rightarrow \mathrm{BNBBr}_{2} *+\mathrm{HBr}
\end{aligned}
$$

where the asterisks $(*)$ denote the surface species. Olander et al. studied the ALD of $\mathrm{BN}$ in the temperature range of 250 to $750^{\circ} \mathrm{C}$ using $\mathrm{BBr}_{3}$ and $\mathrm{NH}_{3}$ precursors. ${ }^{42}$ The deposited films were found to be turbostratic, but their results indicated that the films were subject to oxidation when exposed to air. However, their study also revealed that the films deposited over $600^{\circ} \mathrm{C}$ were more stable, and the best material properties were obtained for fresh samples deposited at the temperature of $750^{\circ} \mathrm{C}$. Mårlid et al. also deposited $\mathrm{BN}$ using a similar ALD process from $\mathrm{BBr}_{3}$ and $\mathrm{NH}_{3}$ and obtained near stoichiometric, transparent and smooth turbostratic films. ${ }^{43}$ They also showed that the sensitivity of BN ultra-thin films to air and moisture can be reduced when using the deposition temperature of $750^{\circ} \mathrm{C}$.

In this work, we synthesize BN membranes and study the ionic transport inside a single nanopore using both experiments and molecular dynamic simulations. First, we present and develop an innovative ALD process based on the use of $\mathrm{BBr}_{3}$ and $\mathrm{NH}_{3}$ in order to synthesize BN thin films. The deposited films were characterized in terms of thickness, composition and microstructure. We used the process to grow BN films on anodic aluminium oxide (AAO) nanoporous templates, demonstrating the conformality benefit and the scalability of the process for the manufacturing of membranes. The newly developed process was also used to fine-tune the diameter of a fabricated transmembrane nanopore by adjusting the $\mathrm{BN}$ thickness. We then studied the ionic transport properties of sodium chloride through the synthesized BN single nanopore. Finally, we performed molecular dynamic simulations in order to confirm the data measured and bring more understanding to the experimental findings. 
EXPERIMENTAL SECTION

\section{ALD of BN}

All depositions have been carried out in a horizontal, low pressure hot-wall ALD reactor. Boron tribromide $\left(\mathrm{BBr}_{3}\right)$ precursor was purchased from Sigma Aldrich and used as received. ALD of $\mathrm{BN}$ was achieved using sequential exposures of $\mathrm{BBr}_{3}$ and $\mathrm{NH}_{3}$ separated by purge steps of Argon. If not stated otherwise, the typical ALD cycle consisted of $0.1 \mathrm{~s}$ pulse of $\mathrm{BBr}_{3}$, $2 \mathrm{~s}$ exposure, and $5 \mathrm{~s}$ purge, followed by a $3 \mathrm{~s}$ pulse of $\mathrm{NH}_{3}, 5 \mathrm{~s}$ exposure and $5 \mathrm{~s}$ purge with Argon. More details on the ALD reactor and on the process are given in Supporting Information (S1). In order to develop and characterize the ALD process, silicon with native oxide substrates were used. To remove the organic contaminants, the substrates were precleaned in acetone, ethanol and de-ionized water for $5 \mathrm{~min}$ in ultrasonic bath before the depositions.

\section{Characterization of the films}

To evaluate the BN film thickness after the ALD depositions, ex-situ spectroscopic ellipsometry (SE) measurements were carried out using a Semilab GES5E visible ellipsometer $(1.2-5.0 \mathrm{eV})$ at an angle of incidence of $70.1^{\circ}$. For all the films, the empirical Cauchy dispersion formula has been adopted to model the optical properties and the thicknesses. Structural characterizations have been performed using a Scanning Electron Microscopy Zeiss EVO HD-15, equipped with EDX. The composition of the films was analyzed by X-ray photoelectron spectroscopy (XPS) on a Thermo Electron ESCALAB 250, using a Ka Al monochromatic source $(1486.6 \mathrm{eV})$. The analyzed surface was around $400 \mu \mathrm{m}^{2}$. The 
roughness was determined using Atomic Force Microscopy (AFM), over a $5 \mu \mathrm{m}^{2}$ surface, and the images analysis has been achieved with the WSxM 5.0 software. The microstructure of the films was studied using grazing incidence X-ray diffraction (GI-XRD) with a PANAlytical X'pert PRO diffractometer equipped with a X'celerator detector using Ni-filtered $\mathrm{Cu} \mathrm{K} \alpha$ source (1.54 $\AA$ radiation). Moreover, the accuracy of the thickness obtained from SE has been confirmed by X-ray reflectometry (XRR) on the same diffractometer. A JEOL ARM 200F high-resolution transmission electron microscope at $200 \mathrm{kV}$ has been used for the HR-TEM studies. Raman scattering measurements were performed using a Renishaw micro-Raman spectrometer equipped with a confocal microscope (Leica) with the excitation wavelength $488 \mathrm{~nm}$. The water contact angle (WCA) was measured by a contact angle goniometer at 25 ${ }^{\circ} \mathrm{C}$ in an environmental chamber, with $6 \mu \mathrm{L}$ water droplets. The software used for droplet data acquisition was One Touch Grabber. Image J (V1.46) and its plug-in drop_analysis have been employed for the angle determination. The droplets were deposited on different spots of the substrate samples, and the left and right contact angles were measured and averaged. In total, 6 measurements were carried out for each sample and averaged in order to obtain the WCA value. Finally, the Fourier Transform Infra-Red (FT-IR) studies have been performed ex-situ on a Thermo Fisher Nexus (using 32 scans).

\section{Nanoporous membranes}

The single nanopore samples are designed in Si/SiNx substrates $\left(2 \mathrm{~cm}^{2}\right)$ presenting a central $200 \mathrm{~nm}$ thick SiNx window $\left(1 \mathrm{~mm}^{2}\right)$. The SiNx membrane windows are manufactured by photolithography and etching processes, using $\mathrm{KOH}$ to etch the silicon and Reactive Ion Etching (RIE) to etch the SiNx. A single hole with a diameter of $100 \pm 20 \mathrm{~nm}$ is then milled 
through the centre of the SiNx membrane window by a gallium focused ion beam (FIB) in order to obtain the transmembrane nanopore. A Lyra Tescan FIBSEM was used. The Ga-FIB was operated at $30 \mathrm{keV}$ ion energy and about $10 \mathrm{pA}$ current with a software specified spot size of $8.6 \mathrm{~nm}$. A filled circle pattern was scanned with a diameter of $80 \mathrm{~nm}$ for about 1.4 seconds. FIB focus and astigmatism adjustments were performed on the Si substrate support close to the membrane window prior to milling.

The anodic aluminium oxide (AAO) nanoporous templates were composed of a highpurity alumina matrix ( $25 \mathrm{~mm}$ wide), $600 \mu \mathrm{m}$ thick, presenting a high pore density ( $10^{9}$ pores $/ \mathrm{cm}^{2}$ ) and an average pore diameter of $200 \mathrm{~nm}$. These inorganic membranes were manufactured electrochemically and purchased from GE Healthcare UK (Whatman Anodisc 25).

\section{Ionic current measurements}

Ionic current measurement was performed using a patch-clamp amplifier (EPC10, HEKA electronics, Germany). The single nanopore was placed between two chambers containing $\mathrm{NaCl}$ solution at different concentrations from $10^{-4}$ to 2 mol.L-1. The cell is sealed on both sides with two O-rings. The current was measured by using an $\mathrm{Ag} / \mathrm{AgCl}$ electrode. The current is measured under constant voltage (from - $100 \mathrm{mV}$ to $100 \mathrm{mV}$ step $10 \mathrm{mV}$ ) during 10 $\mathrm{s}$ and with a sampling rate of $100 \mathrm{kHz}$ using the Patchmaster software (Heka Elektronik, Germany). Each measurement was repeated 3 times. A filter of $10 \mathrm{kHz}$ is applied in order to reduce the noise. The mean value of current and voltage are extracted from current trace using a Fitmaster (Heka Elektronik, Germany). 


\section{Simulations}

Periodic boundary conditions were used in the simulations to model an infinite nanopore. The periodic system was composed of a boron nitride nanotube of $8.5 \mathrm{~nm}$ in length and $10 \mathrm{~nm}$ in diameter. The $\mathrm{B}$ or $\mathrm{N}$ atoms of the nanotube were charged homogenously according to density functional theory (neutral nanopore) or with varying negative charge leading to total surface charge density of $-0.48 \mathrm{C} \cdot \mathrm{m}^{-2}$ or $-0.07 \mathrm{C} . \mathrm{m}^{-2}$, equally distributed on the atoms.

All the systems were neutralized by counter ions while hydrating. For the homogeneously charged nanotube, 398 sodium ions were added to neutralize the high charged tube while only 57 were used in the case of the low charged nanotube. Then $\mathrm{NaCl}$ was added to the system to increase the ionic salt concentration in the simulations.

Parameters for the atoms were taken from the CHARMM27 force field and the TIP3P model for water molecules was used. Each atom of the nanopore was kept fixed to prevent mechanical stress on the water/ion diffusion. When equilibrated, the simulations were continued for $5 \mathrm{~ns}$ before the influence of a voltage ramp application was studied to explore the resulting ionic currents. For each voltage, we performed 20 ns of simulation time during four independent runs in order to ensure enough statistics for the current evaluation. The volume of the simulations was held constant (NVT ensemble) when applying the electric field, and the cell dimensions were set at the final cell dimensions of the equilibration simulations. For all simulations, we used NAMD 2.9 with a constant temperature of $300 \mathrm{~K}$ maintained by the Langevin dynamics method. The parameters of the simulation were chosen as follow: 1 fs time steps, cut-off distance of $12 \AA$, switching distance of $10 \AA$ and pair list distance of $13.5 \AA$ A. A Particle Ewald mesh was used to calculate long-range electrostatic 
interactions and the pressure was maintained constant at 1 bar using a Langevin piston during equilibration (NPT ensemble).

\section{RESULTS AND DISCUSSION}

\section{ALD of BN}

\subsection{Process development}

In this work, we developed an ALD process based on $\mathrm{BBr}_{3}$ and $\mathrm{NH}_{3}$ in order to synthesize $\mathrm{BN}$ thin films, similarly to Mårlid et al. ${ }^{43}$ The sequential exposures of $\mathrm{BBr}_{3}$ and $\mathrm{NH}_{3}$ were separated by argon purges. The surface saturation by the $\mathrm{BBr}_{3}$ precursor was first studied. The very high vapor pressure of $\mathrm{BBr}_{3}$ allows for the use of short pulses of $0.1 \mathrm{~s}$. This pulse was followed by an exposure time before the purge step, in order to leave time for the surface reactions to take place. Figure 1 a depicts the growth rate of the $\mathrm{BN}$ films as a function of $\mathrm{BBr}_{3}$ exposure. Spectroscopic ellipsometry (SE) measurements were used to determine the thicknesses of the films. Using silica substrates at the temperature of $750^{\circ} \mathrm{C}$, the pulse of $0.1 \mathrm{~s}$ and $2 \mathrm{~s}$ exposure were found to be sufficient to achieve saturation. The very high vapor pressure of $\mathrm{BBr}_{3}$ allows for a fast saturation of the surface. This case is actually comparable to ALD of $\mathrm{Al}_{2} \mathrm{O}_{3}$ from Trimethylalumina (TMA) and water, where TMA pulses in the order of milliseconds are sufficient to reach saturation as well. ${ }^{51}$ An ammonia pulse of $5 \mathrm{~s}$ followed by $5 \mathrm{~s}$ exposure was used, as longer pulses or exposures did not lead to thicker films. The saturated growth rate obtained was $0.08 \mathrm{~nm} /$ cycle, which is in the same order of magnitude as the 0.05 and $0.10 \mathrm{~nm} /$ cycle obtained by the group of Uppsala university using similar processes. ${ }^{42-43}$ 

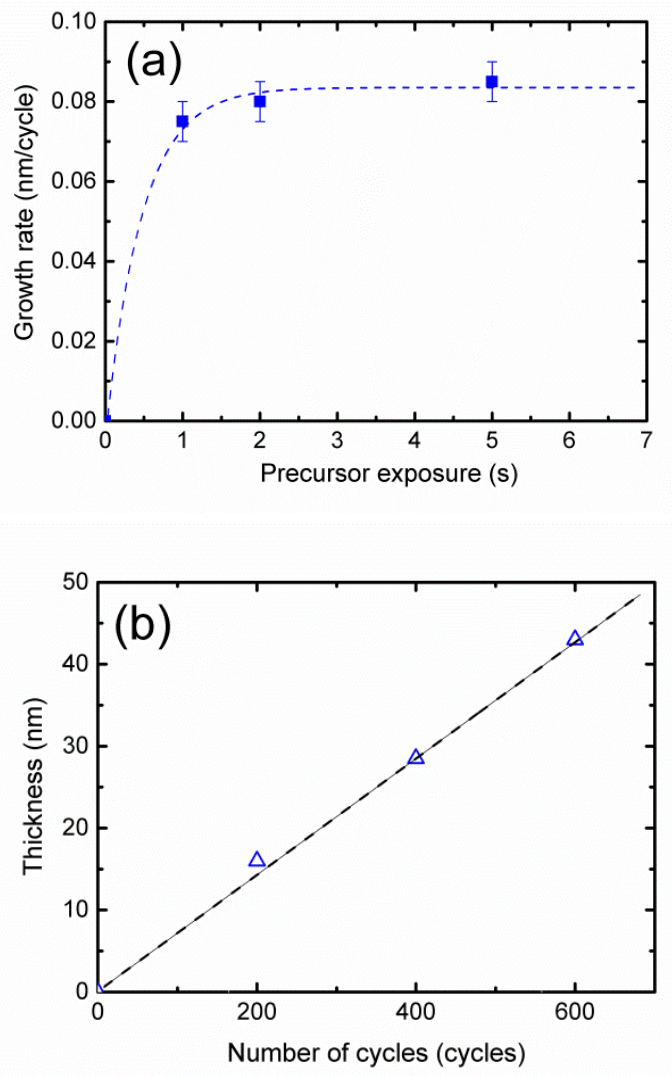

Figure 1. (a) Growth rate as a function of $\mathrm{BBr}_{3}$ exposure time. (b) Thickness as a function of the number of cycles. The substrates were silicon with a native oxide layer and the deposition temperature was $750^{\circ} \mathrm{C}$. Spectroscopic ellipsometry measurements were used to determine the thicknesses of the films. Lines serve as guides to the eyes.

As shown in Figure 1b, the process showed a linear increase in film thickness as a function of ALD cycles with no visible nucleation delay, which is an indication of a good ALD process. Furthermore, we also used the as-described new process to coat electrospun carbon fibers. ${ }^{52}$ As the process is self-limiting and based on surface reactions, the BN layer is covering the fibers in a conformal fashion. This can be observed in the Scanning Electron Microscopy (SEM) image given in Figure S2. 


\subsection{Material characterization}

The chemical composition has been determined using X-ray Photoelectron Spectroscopy (XPS). The synthesized film was $\sim 25 \mathrm{~nm}$ thick and was analyzed after 3 days exposure to air in order to obtain a glance on its stability, and sputtered for $60 \mathrm{~s}$ in order to remove the surface contamination layer before the analysis. The $\mathrm{BN}$ thin film was slightly over-stoichiometric with a $\mathrm{B} / \mathrm{N}$ ratio of 1.2. This slight over-stoichiometry has been observed by others as well, and can be related to the fact that BN ultra-thin films can suffer from a (preferential) loss of nitrogen during the sputtering. ${ }^{43}$ The concentrations of $\mathrm{C}$ and $\mathrm{O}$ contaminants were relatively low even after 3 days exposure to air. The atomic concentrations found were $4 \%$ and $7 \%$, for $\mathrm{C}$ and $\mathrm{O}$, respectively, and no $\mathrm{Br}$ was found in the films (within the detection limit). The XPS spectra can be found on the Figure S3. Atomic Force Microscopy (AFM) has been performed in order to determine the roughness of the deposited films. A RMS roughness of $0.9 \pm 0.3 \mathrm{~nm}$ for a $24 \mathrm{~nm}$ thick film was found. This roughness increased to $1.6 \pm 0.5 \mathrm{~nm}$ for $29 \mathrm{~nm}$ films and reached a value of $2.0 \pm 0.5 \mathrm{~nm}$ for a $40 \mathrm{~nm}$ thick film, which demonstrates that ALD is a technique that can be used to synthesize smooth BN films. The microstructure of the $40 \mathrm{~nm}$ thick film was then examined. To achieve this purpose, X-ray Diffraction (XRD) has been carried out. The grazing-incidence XRD patterns obtained did not reveal any peaks, indicating films with nanocrystal size smaller than the XRD detection limit or even amorphous phase of BN films. More in-depth studies with High Resolution Transmission Electron Microscopy (HR-TEM) have also been performed on a $25 \mathrm{~nm}$ thick BN sample deposited by $A L D$, and the images obtained revealed a turbostratic microstructure (Figure $2 \mathrm{a}$ ) and small areas of $\sim 5-7 \mathrm{~nm}$ size of BN planes can be 
clearly seen. HRTEM and electron diffraction analysis show that the average spacing between the adjacent fringes is $0.37 \pm 0.01 \mathrm{~nm}$ which is close to reported values for turbostratic $\mathrm{BN}$ materials (t-BN, $\mathrm{d}=0.36 \mathrm{~nm}$ ). ${ }^{53}$ In order to reveal the $\mathrm{BN}$ phase of the obtained samples, Raman spectroscopy has been performed on a $\sim 25 \mathrm{~nm}$ thick BN sample. It is known that the $E_{2 g}$ vibrational mode for bulk $h-B N$ appears at approximately $1366 \mathrm{~cm}^{-1}$ and shifts to a higher frequency as the number of h-BN layers decreases. ${ }^{54}$ The Raman spectrum shown in Figure $2 \mathrm{~b}$ exhibits a weak peak at $1372 \mathrm{~cm}^{-1}$, which is consistent with previous report for monolayer h-BN films. ${ }^{55}$ However, the full width at half maximum (FWHM) is rather broad $\left(41 \pm 3 \mathrm{~cm}^{-1}\right)$ when compared to a high-purity h-BN single layer (FWHM $=14 \pm 3 \mathrm{~cm}^{-1}$ ). This peak broadening might be explained by the size reduction of the ordered BN phase ${ }^{56},{ }^{56-57}$ which is confirmed by the results obtained by HRTEM.
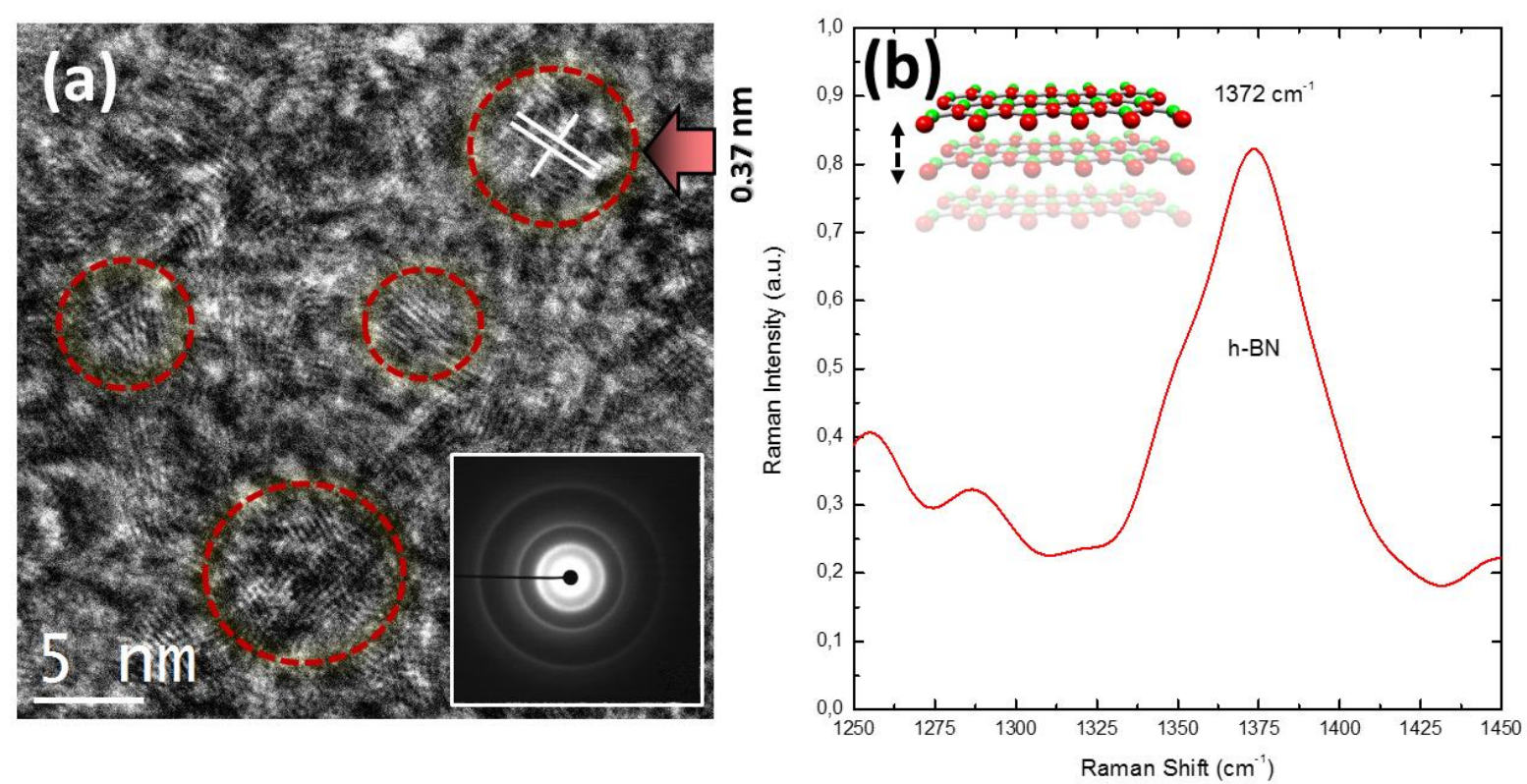

Figure 2. (a) High resolution TEM image of a BN film deposited by ALD on carbon fibers (inset: electron diffraction image). The red circles highlight the presence of BN crystalline 
planes; (b) Normalized Raman spectra demonstrating the presence of h-BN on a BN ALD sample prepared on Si.

Concerning the orientation of the crystalline domains, the microstructure of the BN obtained is turbostratic and the BN planes are randomly oriented (there is no visible preferential orientation, as confirmed by the TEM image). A further step would be to improve the imperfect turbostratic structure. Different studies have been carried out to define the crystallographic changes of $\mathrm{BN}$ with increasing temperature treatments, and it has been shown that starting from imperfect turbostratic microstructure, the heat treatments promoted the ordering of $\mathrm{BN}$ structure and can lead to hexagonal and crystalline $\mathrm{BN} .^{58-61}$ These annealing treatments will be the subjects of further studies.

Next, Fourier transform infrared (FTIR) spectroscopy has been carried out in order to further characterize the synthesized film chemistry. In particular, FTIR allows the study of the BN lattice vibration modes which are due to the stretching of the bonds between the nitrogen and boron atoms. Figure 3 presents the FT-IR transmission spectra of a $40 \mathrm{~nm} \mathrm{BN}$ film grown by $A L D$ at $750^{\circ} \mathrm{C}$.

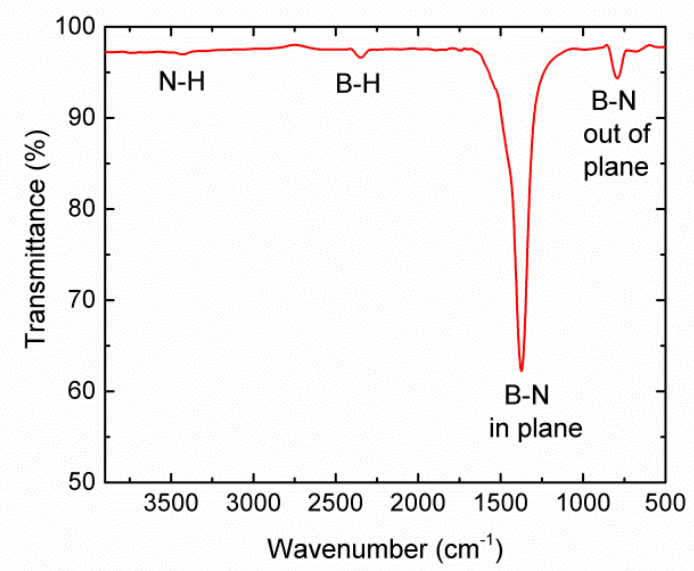


Figure 3. Infrared transmission spectra of a $40 \mathrm{~nm} \mathrm{BN}$ film grown by ALD at $750^{\circ} \mathrm{C}$. A blank Si substrate was used as the background.

The IR spectrum presents the characteristic peaks of h-BN with a weak but noticeable amount of hydrogen detected as $\mathrm{N}-\mathrm{H}$ and $\mathrm{B}-\mathrm{H}$ bands. The strong absorption band centered at $1370 \mathrm{~cm}^{-1}$ can be assigned to the in-plane ring vibration of h-BN (E2g mode of sp2 BN), and the vibration peak centered around $823 \mathrm{~cm}^{-1}$ is characteristic for the out-of-plane h-BN vibration. ${ }^{62-63}$ The peak seen at $2411 \mathrm{~cm}^{-1}$ and the weak bands at $3429 \mathrm{~cm}^{-1}$ can be assigned to the stretching vibrations $\mathrm{B}-\mathrm{H}$ and $\mathrm{N}-\mathrm{H}$, respectively. ${ }^{64}$ The presence of the $\mathrm{B}-\mathrm{H}$ and $\mathrm{N}-\mathrm{H}$ vibrations may be related to the amorphous phases in the turbostratic structure. ${ }^{65-66}$ In addition, the wetting of the material has been estimated by the sessile drop technique, using a contact angle goniometer at $25^{\circ} \mathrm{C}$ in an environmental chamber. A contact angle of $81 \pm 3^{\circ}$ has been measured. This contact angle value shows that the BN material prepared is not hydrophilic.

Finally, as the stability of BN layers prepared by ALD will be tested under saline conditions, initial stability studies have been performed and revealed that the thickness of the films is constant for at least 3 days in $\mathrm{NaCl}$ solution (concentration 1 mol. $\mathrm{L}^{-1}$ ) at room temperature.

\section{Membrane fabrication and surface coating by BN}

As the conformality benefit of BN ALD has not been yet reported, we used the process to grow $B N$ films on anodic aluminium oxide ( $A A O)$ nanoporous templates. The $A A O$ 
nanopores may have extremely high aspect ratios (as high as $\mathrm{L} / \mathrm{d} \sim 10^{4}$ ) and are ideally suited for many technological applications such as nanoscale templates, chemical filters, sensors and membranes. Figure $4 a$ and $4 b$ presents SEM images of such an AAO template before and after the deposition of 500 cycles of BN ALD.

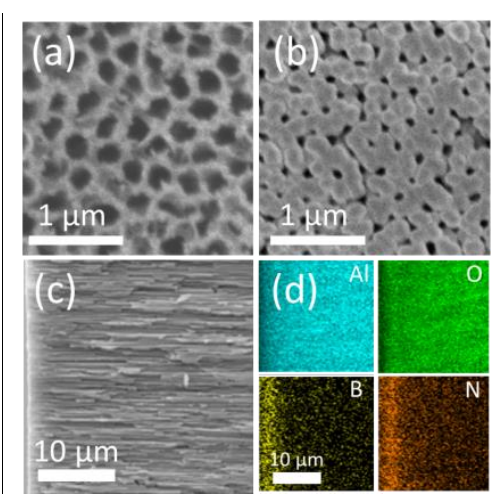

Figure 4. SEM images of anodic aluminum oxide nanoporous templates before (a) and after (b) deposition of BN coatings by ALD. (c) Cross-section SEM image after ALD (d) corresponding cross-section EDX maps of the ALD coated nanopores. The blue, green, yellow and orange dots represent the concentrations of $\mathrm{Al}, \mathrm{O}, \mathrm{B}$ and $\mathrm{N}$ atoms, respectively, and the edge of the AAO is on the left side (for (c) and (d)).

The difference between the two images clearly reveals the deposition of the film on the AAO template pores and the reduction of their diameters. In order to evaluate the penetration of the $\mathrm{BN}$ coatings within the pores, we carried out cross section elemental EDX mapping of the template. Figure $4 \mathrm{c}$ presents the cross section of the AAO and Figure $4 \mathrm{~d}$ depicts the corresponding elemental maps of the coated AAO, where the density of the blue, green, yellow and orange dots represent the concentrations of $\mathrm{Al}, \mathrm{O}, \mathrm{B}$ and $\mathrm{N}$ atoms, respectively. The edge of the AAO is on the left side in the images. It can be seen from the images in Figure $4 \mathrm{~d}$ that the concentration of $\mathrm{B}$ and $\mathrm{N}$ atoms is high up to approximately 4 
$\mu \mathrm{m}$ within the pores. As the initial average pore diameter was $200 \mathrm{~nm}$ (which reduces with the increasing number of ALD cycles), this ALD process can thus be used to coat nanopores with an aspect ratio of up to $\sim 20$. In addition, it is likely that this coated aspect ratio could be further enhanced by increasing the ALD cycle exposure times, as it has been shown for other ALD processes. ${ }^{33}$ This finding confirms further the conformality benefit of the BN ALD process developed, and demonstrates the ability of ALD to coat this type of 3D substrates and the scalability of the process for the manufacturing of membranes. In addition, it confirms the fact that the process developed enables the conformal coating of the transmembrane nanopores in which the ionic conductivity will be studied, as they present a pore length to pore diameter aspect ratio of approximately $L / d \sim 2$ to 3 .

In fact, as one aim of this study is the evaluation of the ionic transport properties through BN nanopores, we used the ALD process described above to coat a single transmembrane nanopore and tune its diameter. The single nanopore presented a diameter of $100 \pm 20 \mathrm{~nm}$. The SEM image of the obtained pore is given in Figure S4. Next, we reduced the initial nanopore diameter from $100 \mathrm{~nm}$ to $20 \mathrm{~nm}$ by applying 500 ALD cycles. The ionic conductivity of the synthesized transmembrane nanopore coated by ALD is then measured.

\section{$3 \quad$ lonic transport across single BN nanopore}

In order to investigate the ionic transport properties, the single BN nanopore membrane was placed between two reservoirs in Teflon. The schematic representation of this cell is depicted in Figure 5a. First, we filled the nanopore with ethanol to ensure the wettability, because of the limited hydrophilicity of the BN material (contact angle $81^{\circ}$ ). The ethanol was then progressively replaced by milliQ water, which was then replaced by $\mathrm{NaCl}$ 
solutions. The ionic current is measured under a constant voltage from -100 mV to $100 \mathrm{mV}$ using $10 \mathrm{mV}$ steps (Figure 5b) during $10 \mathrm{~s}$ (sampling rate $100 \mathrm{kHz}$ ) at varying $\mathrm{NaCl}$ concentrations from $1.10^{-4}$ to $2 \mathrm{~mol} \mathrm{~L}^{-1}$. The $\mathrm{NaCl}$ conductance through the $\mathrm{BN}$ nanopore is directly extracted from the linear IV dependence.
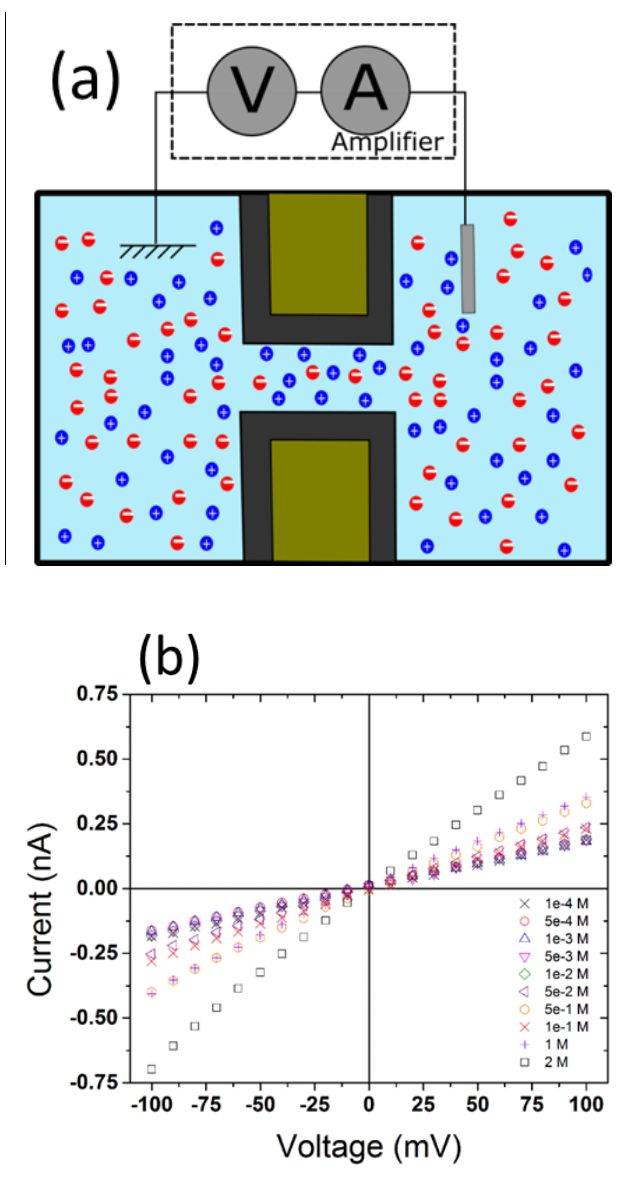

(c)

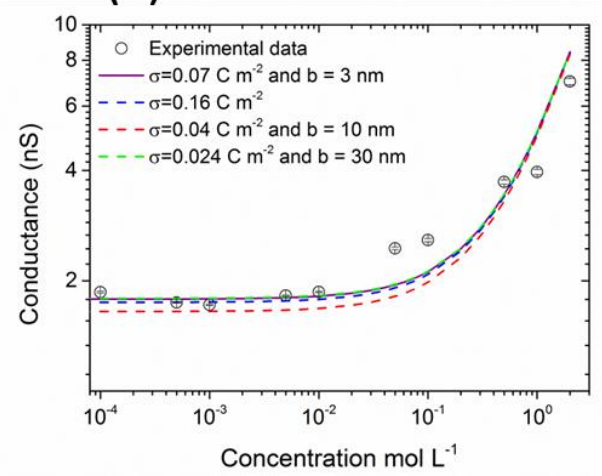


Figure 5. (a) Schematic representation of a fluidic cell connected to the patch-clamp amplifier (b) IV curve for different $\mathrm{NaCl}$ concentrations. (c) conductance vs $\mathrm{NaCl}$ concentration at $\mathrm{pH}=7$ for nanopores with diameter of $10 \mathrm{~nm}$; experimental curve (black circles) and theoretical curves using equation 3 (blue, $\sigma=0.16 \mathrm{C} . \mathrm{m}^{-2}$ ), and equation 13 and 14 of the reference ${ }^{30}$ with varying parameters, see legend.

The nanopore conductance is reported as function of $\mathrm{NaCl}$ concentration in Figure $5 \mathrm{c}$. As commonly observed for a charged nanopore, the conductance follows two distinct regimes. ${ }^{67}$ For salt concentrations below $0.01 \mathrm{~mol}^{\mathrm{L}} \mathrm{L}^{-1}$, the conductance is independent of the $\mathrm{NaCl}$ concentration in the reservoir. In this regime, the ionic conductance is mainly due to the mobile counter ions which ensure the electro neutrality within the nanopore surface. At salt concentrations higher than $0.01 \mathrm{~mol}^{-1} \mathrm{~L}^{-1}$, the conductance increases with the $\mathrm{NaCl}$ reservoir concentration. From this dependence, we extract a nanopore diameter measuring around $10 \mathrm{~nm}$ assuming the ion mobility like bulk. This value is in agreement with the expected one considering the error margin of the initial FIB milled pore diameter of $100 \pm 20$ $\mathrm{nm}$. Interestingly, we can observe that the nanopore conductances are in the same order of magnitude for salt concentration from $10^{-4}$ to 1 mol. $\mathrm{L}^{-1}$, and this trend is similar than previously reported for $\mathrm{BN}$ nanotubes. ${ }^{15}$

Next, we estimate the surface charge of the nanopore using the conductance equation below (3).

$\mathrm{G}=\frac{\pi \mathrm{R}}{\mathrm{L}}\left(\mathrm{R} \kappa_{\mathrm{b}}+\frac{\mu_{ \pm} \sigma}{2}\right)$ 
Where $G$ is the ionic conductance, $R$ the radius and $L$ the length of the pore. $\sigma$ is the nanopore surface charge and $\kappa_{b}=e^{2}\left(\mu_{+}+\mu_{-}\right) c_{b}$ is the bulk conductivity, $e$ is the elementary charge and $\mu$ the ion mobility. A surface charge of $\sigma=0.16 \mathrm{C} \cdot \mathrm{m}^{-2}$ has been obtained for the measured nanopore, which corresponds to 1.1 charges per $\mathrm{nm}^{2}$. This high value is in the same order of magnitude as the ones reported by Siria et al. for a BN nanotube (diameter $15 \mathrm{~nm}$ at $\mathrm{pH}=5$ ). ${ }^{15}$ However, it can be noticed that the surface charge given by equation 3 is overestimated, as this basic model does not take into account the advection, good co-ion exclusion, Debye screening length and slip effects.

In order to provide a better description of the conductivity through the nanopore, we use the hybrid mesoscopic theoretical approach, in the Poisson-Nernst-Planck framework previously proposed by Balme et al. (see equations 13 and 14 of the Reference ${ }^{30}$ ), which includes the influence of slip effects, directly related to the nanopore surface properties. Considering slip lengths (b) of 3.5, 10 and $30 \mathrm{~nm}$, the surface charges obtained are $\sigma=0.07$ C. $\mathrm{m}^{-2}, \sigma=0.04 \mathrm{C} . \mathrm{m}^{-2}$, and $\sigma=0.024 \mathrm{C} . \mathrm{m}^{-2}$, respectively. As the structure of BN is not perfectly crystalline in the case of the ALD coated pore, it is challenging to provide the exact values of the surface charge and the slip length. However, as the BN films obtained present a surface roughness of $\sim 2 \mathrm{~nm}$, we believe that the shortest slip length is the most accurate.

Thus, the conductance at low concentration is mainly due to the surface charge of $\sigma=$ 0.07 C. $\mathrm{m}^{-2}$. This surface charge is comparable to the one reported for a transmembrane BN nanotube $\left(0.1 \mathrm{C} . \mathrm{m}^{-2}\right.$ at $\left.\mathrm{pH} 9.5\right),{ }^{15}$ and is higher than the ones reported for other materials such as PET (Polyethylene terephthalate) track-etched nanopores, where the surface charge is due to carboxylate groups and present values between $0.012 \mathrm{C} . \mathrm{m}^{-2}$ and $0.008 \mathrm{C} . \mathrm{m}^{-2}$ 68-71. It

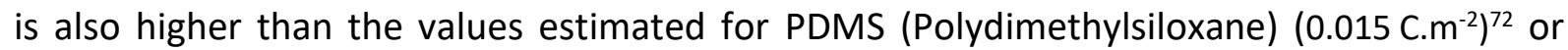


trimetyl-silane $\left(\sigma=0.005 \mathrm{C} . \mathrm{m}^{-2}\right)^{30}$ as well as fused silica $\left(0.06 \mathrm{C} . \mathrm{m}^{-2}\right)^{73}$ or SiN nanopores $(0.02$ C. $\mathrm{m}^{-2}$; diameter $\left.>100 \mathrm{~nm}\right){ }^{74-75}$ It can be noticed that these surface charges were estimated without slip and thus should be compared with the result given by equation 3 ( $\sigma=0.16 \mathrm{C} . \mathrm{m}^{-}$ $\left.{ }^{2}\right)$.

Molecular dynamics simulations (MLD) were also performed to gain more understanding on the ion transport properties and to determine the average charge present on the BN nanopore wall. All simulated nanopores were built according to the hexagonal association of $\mathrm{B}$ and $\mathrm{N}$ atoms. The distances between each atoms were optimized according to quantum calculations and were set to $0.146 \mathrm{~nm} .{ }^{76}$ The nanopore wall was kept fixed in all simulations and periodic boundary conditions were applied to avoid size effects. The size of the (periodic) elementary BN nanopore was set to a diameter of $10 \mathrm{~nm}$ and a length of 8.5 $\mathrm{nm}$ (to limit the duration of the simulations). The simulated $\mathrm{BN}$ nanotube is a perfect honeycomb lattice which is physically charged up homogeneously. The roles of the roughness or of chemical functionalities along the nanopore surface are quite difficult to simulate but they could affect the conductivity. However, as no rectification, blockage nor enhancement was observed in our measurements, we believe that the simulation of a perfect BN wall is relevant. Three different situations were modeled in which the charge conditions on $\mathrm{B}$ and $\mathrm{N}$ atoms were modified. The first set of simulations was based on optimized BN nanotubes by quantum calculations. This first simulation aimed to lead to a neutral BN nanopore with different local charge loads on $B$ and $N$ atoms $(+0.11 e$ and $-0.11 e$ respectively). The second situation considered was a very strongly charged BN nanotube presenting a total charge density of $-0.48 \mathrm{C} . \mathrm{m}^{-2}$ (each atom loading a local charge of $-0.04 \mathrm{e}$ ). Finally, a last situation was simulated, using a charge of -0.005 e for each atom, which led to a total charge equal to $-0.07 \mathrm{C} . \mathrm{m}^{-2}$ for the $\mathrm{BN}$ nanotube. In all situations, we have finally 
solvated the system, added the counter ions necessary to neutralize the system and then added the supplementary salt concentration to mimic at best the experimental conditions. After a fast equilibration simulation ( $1 \mathrm{~ns}$ ) and a running step of $7 \mathrm{~ns}$, the system was submitted to a progressive potential ramp and the electric current was extracted. ${ }^{76}$ Figure 6 depicts the results of the aforementioned simulations.

a)

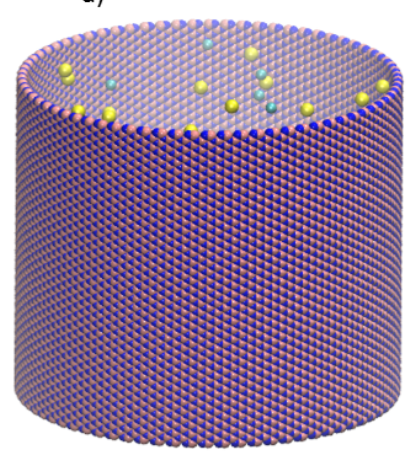

b)

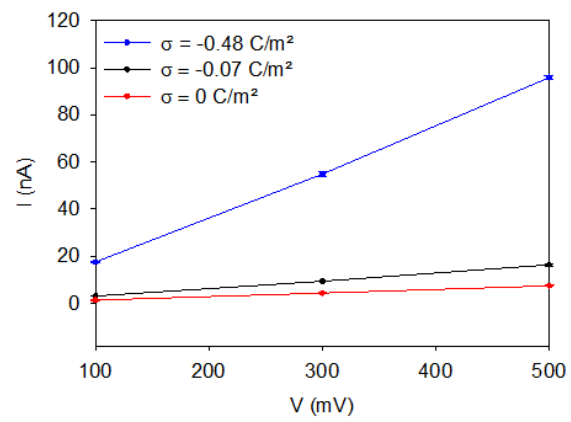

c)

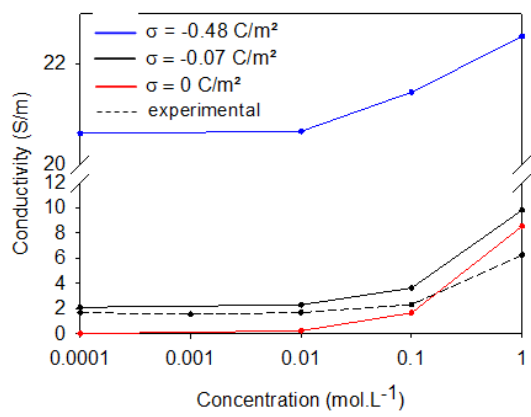

Figure 6. (a) Elementary cell of the simulated $B N$ nanopore $(L=8.5 \mathrm{~nm}$ and $D=10 \mathrm{~nm} ; 0.1$ mol. $\mathrm{L}^{-1} \mathrm{NaCl}$ ). The atoms $\mathrm{N}$ (blue) and $\mathrm{B}\left(\right.$ red) and the counter ions $\mathrm{Na}^{+}$(yellow) and $\mathrm{Cl}^{-}$(blue) are depicted., (b) IV curves obtained for a concentration of 0.1 mol. $\mathrm{L}^{-1}$ and for different conditions of charge of the BN nanopore and (c) Experimental and simulated conductivity for the different conditions of charge of the $\mathrm{BN}$ nanopore and for different salt concentrations.

Figure 6a shows the periodic elementary cell used for the simulated BN nanopore. As can be seen in Figure $6 \mathrm{~b}$, the simulations carried out show that each IV curve presents a linear behavior even for voltages up to $500 \mathrm{mV}$. It is likely that this linearity is due to the uniform distribution of charges along the nanopore wall that does not induce any local 
perturbation on the ion diffusion in the solvent. Figure $6 c$ presents the simulated conductivities for the three different charge conditions of the BN nanotube (neutral, -0.07 C. $\mathrm{m}^{-2}$ and $-0.48 \mathrm{C} . \mathrm{m}^{-2}$ ) as a function of the salt concentration. The experimental curve is also reported in the graph. It is clear from the Figure $6 c$ that the conductivities obtained from the simulated highly charged nanotube $\left(-0.48 \mathrm{C} . \mathrm{m}^{-2}\right)$ do not fit with the experimental data obtained for the nanopore studied, nor does the simulated neutrally charged nanotube. However, when the simulations were performed for a BN nanotube presenting a global charge of $-0.07 \mathrm{C} . \mathrm{m}^{-2}$, the agreement between the experimental and the simulated conductivity is fairly good. Considering our experimental data and the aforementioned simulations, the surface charge density can be considered equal to $-0.07 \mathrm{C} . \mathrm{m}^{-2}$ at $\mathrm{pH}=7$ for the BN nanopore prepared by ALD. This simulation result comforts the theoretical calculations previously given and opens perspectives for BN ALD as a new route for the large scale implementation of BN nanoporous membranes in different applications such ultrafiltration, osmotic energy or ionic separation applications.

\section{CONCLUSIONS}

An atomic layer deposition (ALD) process based on $\mathrm{BBr}_{3}$ and $\mathrm{NH}_{3}$ has been developed and used to prepare boron nitride films and to coat nanoporous membranes. The data show that the BN film thickness is linearly proportional to the number of cycles, with a GPC of $\sim 0.08 \mathrm{~nm}$. The deposited films were smooth, presented a turbostratic microstructure and very low contamination level. The scalability of the process for the manufacturing of membranes was demonstrated by the conformal BN coating of carbon fibers and anodic aluminium oxide (AAO) nanoporous templates. The films were successfully deposited within 
pores presenting aspect ratios of $L / D \sim 20$, and we believe that this coated aspect ratio could be further enhanced by increasing the ALD cycle exposure times. The ALD process was also used to tune the diameter of fabricated transmembrane nanopores by adjusting the $\mathrm{BN}$ thickness, so that the fundamental aspect of the ionic transport of the BN nanopore could be studied. The IV curves were measured depending on the salt concentrations for a nanopore presenting a diameter of $\sim 10 \mathrm{~nm}$. The conductivity values are in the same order of magnitude from $\mathrm{NaCl}$ concentration from $10^{-4}$ to 1 mol. $\mathrm{L}^{-1}$ which is mainly due to a relatively high surface charge density. The latter is estimated to $-0.16 \mathrm{C} . \mathrm{m}^{-2}$ without slip and $-0.07 \mathrm{C} . \mathrm{m}^{-}$ 2 with a slip length of $3 \mathrm{~nm}$. In addition, molecular dynamics simulations have been performed using elementary cells of a BN nanotube mimicking the experimental nanopore. Different situations were modeled in which the charge conditions on $\mathrm{B}$ and $\mathrm{N}$ atoms were modified, and the simulations confirmed the estimated surface charge value. The high surface charge evaluated in the BN nanopore and the ability to design nanoporous membranes by such a scalable method paves the way for the integration of ionic separation and ultrafiltration devices, and provides a roadmap for the large scale fabrication of BN membranes.

\section{ACKNOWLEDGEMENTS}

The authors would like to thank Gerhard Bürki for his technical assistance with the FIB milling. This work was supported by the French Research Program ANR BONALD. The supports of the CNRS PICS "NANOALD", an international cooperation program of the French National Research Center (CNRS) and the COST Action "HERALD", a European cooperation 
program, are acknowledged. Computations have been performed on the supercomputer facilities of the Mesocentre of the University of Franche-Comté.

\section{SUPPORTING INFORMATION}

S1: Description of the ALD reactor and process experimental details ; Figure S2 : SEM images of a BN film prepared on carbon microfibers by ALD ; Figure S3: XPS spectra ; Figure S4: SEM image of the FIB milled nanopore.

\section{REFERENCES}

1. Tian, Y.; Xu, B.; Yu, D.; Ma, Y.; Wang, Y.; Jiang, Y.; Hu, W.; Tang, C.; Gao, Y.; Luo, K. Ultrahard Nanotwinned Cubic Boron Nitride. Nature 2013, 493, 385-388.

2. Dean, C. R.; Young, A. F.; Meric, I.; Lee, C.; Wang, L.; Sorgenfrei, S.; Watanabe, K.; Taniguchi, T.; Kim, P.; Shepard, K. Boron Nitride Substrates for High-Quality Graphene Electronics. Nat. Nanotechnol. 2010, 5, 722-726.

3. Ci, L.; Song, L.; Jin, C.; Jariwala, D.; Wu, D.; Li, Y.; Srivastava, A.; Wang, Z.; Storr, K.; Balicas, L. Atomic Layers of Hybridized Boron Nitride and Graphene Domains. Nat. Mater. 2010, 9, 430-435.

4. Song, L.; Ci, L.; Lu, H.; Sorokin, P. B.; Jin, C.; Ni, J.; Kvashnin, A. G.; Kvashnin, D. G.; Lou, J.; Yakobson, B. I. Large Scale Growth and Characterization of Atomic Hexagonal Boron Nitride Layers. Nano Lett. 2010, 10, 3209-3215.

5. Guo, S.; Meshot, E. R.; Kuykendall, T.; Cabrini, S.; Fornasiero, F. Nanofluidic Transport through Isolated Carbon Nanotube Channels: Advances, Controversies, and Challenges. Adv. Mater. 2015, 27, 5726-5737.

6. $\quad$ Smeets, R. M. M.; Keyser, U. F.; Krapf, D.; Wu, M.-Y.; Dekker, N. H.; Dekker, C. Salt Dependence of Ion Transport and DNA Translocation through Solid-State Nanopores. Nano Lett. 2006, 6, 89-95.

7. Miles, B. N.; Ivanov, A. P.; Wilson, K. A.; Doğan, F.; Japrung, D.; Edel, J. B. Single Molecule Sensing with Solid-State Nanopores: Novel Materials, Methods, and Applications. Chem. Soc. Rev. 2013, 42, 15-28.

8. Wanunu, M. Nanopores: A Journey Towards DNA Sequencing. Phys. Life Rev. 2012, 9, 125158.

9. Lee, K. P.; Mattia, D. Monolithic Nanoporous Alumina Membranes for Ultrafiltration Applications: Characterization, Selectivity-Permeability Analysis and Fouling Studies. J. Memb. Sci. 2013, 435, 52-61.

10. Ahn, H.; Park, S.; Kim, S.-W.; Yoo, P. J.; Ryu, D. Y.; Russell, T. P. Nanoporous Block Copolymer Membranes for Ultrafiltration: A Simple Approach to Size Tunability. ACS Nano 2014, 8, 11745 11752.

11. Liu, D.; He, L.; Lei, W.; Klika, K. D.; Kong, L.; Chen, Y. Multifunctional Polymer/Porous Boron Nitride Nanosheet Membranes for Superior Trapping Emulsified Oils and Organic Molecules. Adv. Mater. Interfaces 2015, 2, 1500228. 
12. Li, J.; Jia, H.; Lin, J.; Luo, H.; Liu, Z.; Xu, X.; Huang, Y.; Jin, P.; Zhang, J.; Abbas, S. Free-Standing Membranes Made of Activated Boron Nitride for Efficient Water Cleaning. RSC Adv. 2015, 5, 7153771543.

13. Garnier, L.; Szymczyk, A.; Malfreyt, P.; Ghoufi, A. Physics Behind Water Transport through Nanoporous Boron Nitride and Graphene. J. Phys. Chem. Lett. 2016, 7, 3371-3376.

14. Surwade, S. P.; Smirnov, S. N.; Vlassiouk, I. V.; Unocic, R. R.; Veith, G. M.; Dai, S.; Mahurin, S. M. Water Desalination Using Nanoporous Single-Layer Graphene. Nat. Nanotechnol. 2015, 10, 459464.

15. Siria, A.; Poncharal, P.; Biance, A. L.; Fulcrand, R.; Blase, X.; Purcell, S. T.; Bocquet, L. Giant Osmotic Energy Conversion Measured in a Single Transmembrane Boron Nitride Nanotube. Nature 2013, 494, 455-458.

16. Xie, G.; Wen, L.; Jiang, L. Biomimetic Smart Nanochannels for Power Harvesting. Nano Res. 2016, 9, 59-71.

17. Feng, J.; Graf, M.; Liu, K.; Ovchinnikov, D.; Dumcenco, D.; Heiranian, M.; Nandigana, V.; Aluru, N. R.; Kis, A.; Radenovic, A. Single-Layer Mos2 Nanopores as Nanopower Generators. Nature 2016, 536, 197-200.

18. Brogioli, D.; Zhao, R.; Biesheuvel, P. A Prototype Cell for Extracting Energy from a Water Salinity Difference by Means of Double Layer Expansion in Nanoporous Carbon Electrodes. Energy Environ. Sci. 2011, 4, 772-777.

19. Skilhagen, S. E.; Dugstad, J. E.; Aaberg, R. J. Osmotic Power - Power Production Based on the Osmotic Pressure Difference between Waters with Varying Salt Gradients. Desalination 2008, 220, 476-482.

20. Skilhagen, S. E. Osmotic Power-a New, Renewable Energy Source. Desalin. Water Treat. 2010, 15, 271-278.

21. Schmidt, T.; Baierle, R.; Piquini, P.; Fazzio, A. Theoretical Study of Native Defects in Bn Nanotubes. Phys. Rev. B 2003, 67, 113407.

22. Lin, Y.; Connell, J. W. Advances in 2d Boron Nitride Nanostructures: Nanosheets, Nanoribbons, Nanomeshes, and Hybrids with Graphene. Nanoscale 2012, 4, 6908-6939.

23. Di Fiori, N.; Squires, A.; Bar, D.; Gilboa, T.; Moustakas, T. D.; Meller, A. Optoelectronic Control of Surface Charge and Translocation Dynamics in Solid-State Nanopores. Nat. Nanotechnol. 2013, 8, 946-951.

24. George, S. M. Atomic Layer Deposition: An Overview. Chem. Rev. 2009, 110, 111-131.

25. Johnson, R. W.; Hultqvist, A.; Bent, S. F. A Brief Review of Atomic Layer Deposition: From Fundamentals to Applications. Mater. Today 2014, 17, 236-246.

26. Leskelä, M.; Ritala, M. Atomic Layer Deposition (Ald): From Precursors to Thin Film Structures. Thin Solid Films 2002, 409, 138-146.

27. Weber, M. J.; Mackus, A. J.; Verheijen, M. A.; van der Marel, C.; Kessels, W. M. Supported Core/Shell Bimetallic Nanoparticles Synthesis by Atomic Layer Deposition. Chem. Mater. 2012, 24, 2973-2977.

28. Weber, M.; Verheijen, M.; Bol, A.; Kessels, W. Sub-Nanometer Dimensions Control of Core/Shell Nanoparticles Prepared by Atomic Layer Deposition. Nanotechnology 2015, 26, 094002.

29. Van Bui, H.; Grillo, F.; van Ommen, R. Atomic and Molecular Layer Deposition: Off the Beaten Track. Chem. Commun. 2017, 53, 45-71.

30. Balme, S.; Picaud, F.; Manghi, M.; Palmeri, J.; Bechelany, M.; Cabello-Aguilar, S.; AbouChaaya, A.; Miele, P.; Balanzat, E.; Janot, J. M. Ionic Transport through Sub-10 Nm Diameter Hydrophobic High-Aspect Ratio Nanopores: Experiment, Theory and Simulation. Sci. Rep. 2015, 5, 10135.

31. Chen, P.; Mitsui, T.; Farmer, D. B.; Golovchenko, J.; Gordon, R. G.; Branton, D. Atomic Layer Deposition to Fine-Tune the Surface Properties and Diameters of Fabricated Nanopores. Nano Lett. 2004, 4, 1333-1337.

32. Abou Chaaya, A.; Le Poitevin, M.; Cabello-Aguilar, S.; Balme, S.; Bechelany, M.; Kraszewski, S.; Picaud, F.; Cambedouzou, J.; Balanzat, E.; Janot, J.-M. Enhanced Ionic Transport Mechanism by 
Gramicidin a Confined inside Nanopores Tuned by Atomic Layer Deposition. J. Phys. Chem. C 2013, $117,15306-15315$.

33. Elam, J. W.; Xiong, G.; Han, C. Y.; Wang, H. H.; Birrell, J. P.; Welp, U.; Hryn, J. N.; Pellin, M. J.; Baumann, T. F.; Poco, J. F. Atomic Layer Deposition for the Conformal Coating of Nanoporous Materials. J. Nanomater. 2006, 2006, 64501.

34. Elam, J.; Routkevitch, D.; Mardilovich, P.; George, S. Conformal Coating on Ultrahigh-AspectRatio Nanopores of Anodic Alumina by Atomic Layer Deposition. Chem. Mater. 2003, 15, 3507-3517. 35. Berland, B.; Gartland, I.; Ott, A.; George, S. In Situ Monitoring of Atomic Layer Controlled Pore Reduction in Alumina Tubular Membranes Using Sequential Surface Reactions. Chem. Mater. 1998, 10, 3941-3950.

36. Niinistö, J.; Kukli, K.; Heikkilä, M.; Ritala, M.; Leskelä, M. Atomic Layer Deposition of High-K Oxides of the Group 4 Metals for Memory Applications. Adv. Eng. Mater. 2009, 11, 223-234.

37. Drobek, M.; Bechelany, M.; Vallicari, C.; Chaaya, A. A.; Charmette, C.; Salvador-Levehang, C.; Miele, P.; Julbe, A. An Innovative Approach for the Preparation of Confined Zif-8 Membranes by Conversion of Zno Ald Layers. J. Memb. Sci. 2015, 475, 39-46.

38. Consiglio, S.; Clark, R. D.; O'Meara, D.; Wajda, C. S.; Tapily, K.; Leusink, G. J. Comparison of B2o3 and Bn Deposited by Atomic Layer Deposition for Forming Ultrashallow Dopant Regions by Solid State Diffusion. J. Vac. Sci. Technol. A 2016, 34, 01A102.

39. Haider, A.; Ozgit-Akgun, C.; Goldenberg, E.; Okyay, A. K.; Biyikli, N.; Brennecka, G. LowTemperature Deposition of Hexagonal Boron Nitride Via Sequential Injection of Triethylboron and N2/H2plasma. J. Am. Ceram. Soc. 2014, 97, 4052-4059.

40. Hemmi, A.; Bernard, C.; Cun, H.; Roth, S.; Klöckner, M.; Kälin, T.; Weinl, M.; Gsell, S.; Schreck, M.; Osterwalder, J. High Quality Single Atomic Layer Deposition of Hexagonal Boron Nitride on Single Crystalline Rh (111) Four-Inch Wafers. Rev. Sci. Instrum. 2014, 85, 035101.

41. Olander, J.; Larsson, K. Cubic Boron Nitride Growth from Nh 3 and Bbr 3 Precursors: A Theoretical Study. Diamond Relat. Mater. 2002, 11, 1286-1289.

42. Olander, J.; Ottosson, L. M.; Heszler, P.; Carlsson, J. O.; Larsson, K. M. Laser-Assisted Atomic Layer Deposition of Boron Nitride Thin Films. Chem. Vap. Deposition 2005, 11, 330-337.

43. Mårlid, B.; Ottosson, M.; Pettersson, U.; Larsson, K.; Carlsson, J.-O. Atomic Layer Deposition of Bn Thin Films. Thin Solid Films 2002, 402, 167-171.

44. Ferguson, J.; Weimer, A.; George, S. Atomic Layer Deposition of Boron Nitride Using Sequential Exposures of Bcl 3 and Nh 3. Thin Solid Films 2002, 413, 16-25.

45. Bjelkevig, C.; Mi, Z.; Xiao, J.; Dowben, P. A.; Wang, L.; Mei, W. N.; Kelber, J. A. Electronic Structure of a Graphene/Hexagonal-Bn Heterostructure Grown on Ru(0001) by Chemical Vapor Deposition and Atomic Layer Deposition: Extrinsically Doped Graphene. J. Phys. Condens. Matter. 2010, 22, 302002.

46. Driver, M. S.; Beatty, J. D.; Olanipekun, O.; Reid, K.; Rath, A.; Voyles, P. M.; Kelber, J. A. Atomic Layer Epitaxy of H-Bn(0001) Multilayers on Co(0001) and Molecular Beam Epitaxy Growth of Graphene on H-Bn(0001)/Co(0001). Langmuir 2016, 32, 2601-2607.

47. Snure, M.; Paduano, Q.; Hamilton, M.; Shoaf, J.; Mann, J. M. Optical Characterization of Nanocrystalline Boron Nitride Thin Films Grown by Atomic Layer Deposition. Thin Solid Films 2014, 571, 51-55.

48. Jones, J.; Beauclair, B.; Olanipekun, O.; Lightbourne, S.; Zhang, M.; Pollok, B.; Pilli, A.; Kelber, J. Atomic Layer Deposition of H-Bn (0001) on Ruo2 (110)/Ru (0001). J. Vac. Sci. Technol. A 2017, 35, 01 1B139.

49. Park, H.; Kim, T. K.; Cho, S. W.; Jang, H. S.; Lee, S. I.; Choi, S.-Y. Large-Scale Synthesis of Uniform Hexagonal Boron Nitride Films by Plasma-Enhanced Atomic Layer Deposition. Sci. Rep. 2017, 7, 40091.

50. Barber, W.; Boynton, C.; Gallagher, P. Physical Properties of Boron Tribromide. J. Chem. Eng. Data 1964, 9, 137-138.

51. Wind, R.; George, S. Quartz Crystal Microbalance Studies of Al2o3 Atomic Layer Deposition Using Trimethylaluminum and Water at 125 C. J. Phys. Chem. A 2009, 114, 1281-1289. 
52. Both Engel, A.; Cherifi, A.; Bechelany, M.; Tingry, S.; Cornu, D. Control of Spatial Organization of Electrospun Fibers in a Carbon Felt for Enhanced Bioelectrode Performance. ChemPlusChem 2015, $80,494-502$.

53. Zhao, Z.; Yang, Z.; Wen, Y.; Wang, Y. Facile Synthesis and Characterization of Hexagonal Boron Nitride Nanoplates by Two-Step Route. J. Am. Ceram. Soc. 2011, 94, 4496-4501.

54. Gorbachev, R. V.; Riaz, I.; Nair, R. R.; Jalil, R.; Britnell, L.; Belle, B. D.; Hill, E. W.; Novoselov, K. S.; Watanabe, K.; Taniguchi, T. Hunting for Monolayer Boron Nitride: Optical and Raman Signatures. Small 2011, 7, 465-468.

55. Stehle, Y.; Meyer III, H. M.; Unocic, R. R.; Kidder, M.; Polizos, G.; Datskos, P. G.; Jackson, R.; Smirnov, S. N.; Vlassiouk, I. V. Synthesis of Hexagonal Boron Nitride Monolayer: Control of Nucleation and Crystal Morphology. Chem. Mater. 2015, 27, 8041-8047.

56. Toury, B.; Miele, P.; Cornu, D.; Vincent, H.; Bouix, J. Boron Nitride Fibers Prepared from Symmetric and Asymmetric Alkylaminoborazines. Adv. Funct. Mater. 2002, 12, 228-234.

57. Nemanich, R.; Solin, S.; Martin, R. M. Light Scattering Study of Boron Nitride Microcrystals. Phys. Rev. B 1981, 23, 6348.

58. Hagio, T.; Nonaka, K.; Sato, T. Microstructural Development with Crystallization of Hexagonal Boron Nitride. J. Mater. Sci. Lett. 1997, 16, 795-798.

59. Li, J.-S.; Zhang, C.-R.; Li, B.; Cao, F.; Wang, S.-Q. Boron Nitride Coatings by Chemical Vapor Deposition from Borazine. Surf. Coat. Technol. 2011, 205, 3736-3741.

60. Solozhenko, V. L.; Turkevich, V. Z.; Holzapfel, W. B. Refined Phase Diagram of Boron Nitride. J. Phys. Chem. B 1999, 103, 2903-2905.

61. Jin, Y.; Yasuhara, S.; Shimizu, T.; Yang, M. In Deposition of Boron Nitride Films by FilamentAssisted Cvd Using Tris (Bimethylamino) Borane Precursor, Key Engineering Materials, Trans. Tech. Publ. 2015; 142-148.

62. Geick, R.; Perry, C.; Rupprecht, G. Normal Modes in Hexagonal Boron Nitride. Phys. Rev. 1966, 146, 543.

63. Shi, Y.; Hamsen, C.; Jia, X.; Kim, K. K.; Reina, A.; Hofmann, M.; Hsu, A. L.; Zhang, K.; Li, H.; Juang, Z. Y.; Dresselhaus, M. S.; Li, L. J.; Kong, J. Synthesis of Few-Layer Hexagonal Boron Nitride Thin Film by Chemical Vapor Deposition. Nano Lett. 2010, 10, 4134-4139.

64. Rye, R. R. Hot Filament Activated Chemical Vapor Deposition of Boron Nitride. J. Vac. Sci. Technol. A 1991, 9, 1099-1103.

65. Rozenberg, A.; Sinenko, Y. A.; Chukanov, N. Ir Spectroscopy Characterization of Various Types of Structural Irregularities in Pyrolytic Boron Nitride. J. Mater. Sci. 1993, 28, 5675-5678.

66. Zedlitz, R.; Heintze, M.; Schubert, M. Properties of Amorphous Boron Nitride Thin Films. J. Non-Cryst. Solids 1996, 198, 403-406.

67. Schoch, R. B.; Han, J.; Renaud, P. Transport Phenomena in Nanofluidics. Rev. Mod. Phys. 2008, 80, 839.

68. Déjardin, P.; Vasina, E. N.; Berezkin, V. V.; Sobolev, V. D.; Volkov, V. I. Streaming Potential in Cylindrical Pores of Poly (Ethylene Terephthalate) Track-Etched Membranes: Variation of Apparent Z Potential with Pore Radius. Langmuir 2005, 21, 4680-4685.

69. Cervera, J.; Alcaraz, A.; Schiedt, B.; Neumann, R.; Ramirez, P. Asymmetric Selectivity of Synthetic Conical Nanopores Probed by Reversal Potential Measurements. J. Phys. Chem. C 2007, $111,12265-12273$.

70. Ramírez, P.; Apel, P. Y.; Cervera, J.; Mafé, S. Pore Structure and Function of Synthetic Nanopores with Fixed Charges: Tip Shape and Rectification Properties. Nanotechnology 2008, 19, 315707.

71. Xue, J.; Xie, Y.; Yan, Y.; Ke, J.; Wang, Y. Surface Charge Density of the Track-Etched Nanopores in Polyethylene Terephthalate Foils. Biomicrofluidics 2009, 3, 022408.

72. Shimizu, S.; Ellison, M.; Aziz, K.; Wang, Q. H.; Ulissi, Z.; Gunther, Z.; Bellisario, D.; Strano, M. Stochastic Pore Blocking and Gating in Pdms-Glass Nanopores from Vapor-Liquid Phase Transitions. J. Phys. Chem. C 2013, 117, 9641-9651. 
73. Stein, D.; Kruithof, M.; Dekker, C. Surface-Charge-Governed lon Transport in Nanofluidic Channels. Phys. Rev. Lett. 2004, 93, 035901.

74. Lee, C.; Joly, L.; Siria, A.; Biance, A.-L.; Fulcrand, R. m.; Bocquet, L. r. Large Apparent Electric Size of Solid-State Nanopores Due to Spatially Extended Surface Conduction. Nano Lett. 2012, 12, 4037-4044.

75. Hyun, C.; Rollings, R.; Li, J. Probing Access Resistance of Solid-State Nanopores with a Scanning-Probe Microscope Tip. Small 2012, 8, 385-392.

76. El Khalifi, M.; Bentin, J.; Duverger, E.; Gharbi, T.; Boulahdour, H.; Picaud, F. Encapsulation Capacity and Natural Payload Delivery of an Anticancer Drug from Boron Nitride Nanotube. Phys. Chem. Chem. Phys. 2016, 18, 24994-25001.

\section{TABLE OF CONTENTS}
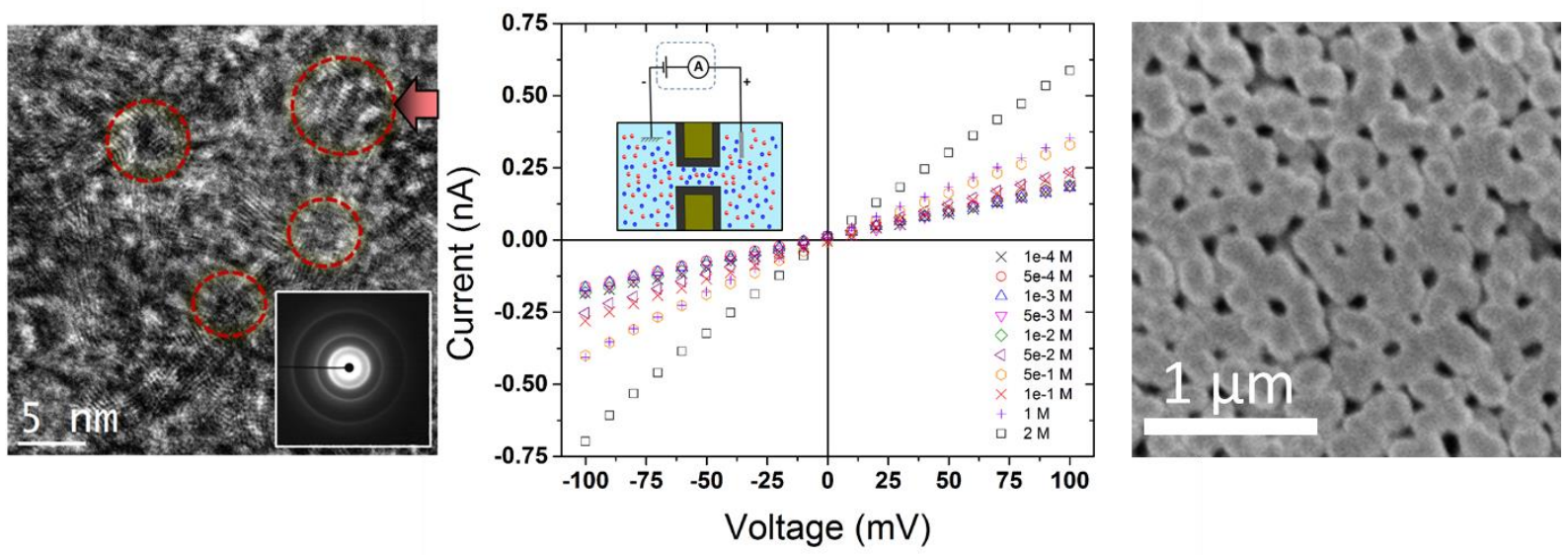